\title{
MEDICO-LEGAL IMPLICATIONS OF DENTAL PRENATAL AGE ESTIMATION WITH REFERENCE TO A CASE REPORT
}

P. Nambiar, G. Paul, D. Swaminathan, K. Nadesan. Medico-legal implications of dental prenatal age estimation with reference to a case report. Annal Dent Univ Malaya 2000; 7: 46-50.

\begin{abstract}
The estimation of age of human foetal remains is of great medico-legal importance. When the remains are intact and fresh, various morphological features such as crown-heel length, weight, appearance of ossification centres particularly around the ankles and knees and other parameters could be used to make a reasonable estimation of the period of gestation. In cases of criminal abortion, infanticide and child murder the question of age of the foetus, viability, live birth and a separate existence become very important. In practice, often at the time of detection, the remains are decomposed or skeletonised. In such a situation the examination of developing teeth will provide a reliable answer pertaining to the foetal age, the possibility of a separate existence and even the period of survival after birth. The age determination from dental examination is possible from approximately 10 weeks intrauterine up to old age. The presence of neonatal line (birth line) in both dentine and enamel indicates live birth and a separate existence. It is possible that the time period of survival can be estimated by measuring postnatal deposition of these hard tissues. An intact human foetus that has undergone mild to moderate putrefaction was studied. The study of the morphological features and the ossification centres suggested that its approximate age was around nine months intrauterine. It was not possible to decide whether it was a live birth and had a separate existence. The examination of the developing first deciduous molar of the mandible suggested the approximate age was around 30-32 weeks intrauterine. The importance of examination of developing teeth in foetal remains (including neonates), particularly associated with putrefaction or skeletonisation is emphasized.
\end{abstract}

Key words: Dental age, forensic odontology, forensic medicine, medico-legal, infanticide

\section{INTRODUCTION}

The uncovering of human skeletal parts that are not buried at appropriate burial sites or concealed in unusual places result in a criminal investigation. Accurate determination of the age of the individual is an important part of the process of identification of the person. Age assessment is one of the important problems of forensic medicine and forensic odontology in particular (1). Teeth, which provide the life history of an individual,
Case Report

P. Nambiar ${ }^{1}$, G. Paul $^{2}$, D. Swaminathan ${ }^{3}$ and $\mathrm{K}$. Nadesan ${ }^{2}$

IDepartment of Oral Biology,

Faculty of Dentistry,

2Department of Pathology (Forensic section), Faculty of Medicine,

${ }^{3}$ Department of Oral Pathology,

Oral Medicine and Periodontology,

Faculty of Dentistry,

University of Malaya, 50603 Kuala Lumpur. .

Corresponding author - P. Nambiar

contributes as a reliable means of determining age from foetal stage (approximately 10 weeks intrauterine) up to old age (2). Dental development data are usually based on formative or development changes, and are good predictors of age from in-utero until about early twenties. The various sequences observed are:

(a) soft tissue proliferation (histological premineralization sequences).

(b) histological mineralization.

(c) incremental patterns of dentine and enamel formation.

(d) emergence of teeth into oral cavity.

(e) apical closure of the roots.

The primary human dentition is initiated at approximately 6 weeks of intrauterine life by a downgrowth of epithelial cells from the oral epithelium in the anterior region of the jaws to form the dental lamina. This downgrowth occurs under the influence of ectomesenchymal cells from the neural crest. Further interaction between the epithelium of the dental lamina and ectomesenchyme results in the formation of tooth buds and the specific tooth forms. Human dental development begins with the formation of deciduous incisors, followed by the first molar, canine and second molar. Subsequently the permanent dentition replaces them in a predetermined order. During the 12 th week, the first and second deciduous maxillary and mandibular molars initiate their soft tissue crown formation. Initial calcification of the mesiobuccal cusp of the 1st molar occurs at $151 / 2$ weeks intrauterine, followed by the mesiolingual cusp and then the distal cusps (3). Mineralization of teeth starts with dentine and subsequently enamel formation follows. Histological examination is very sensitive during this period of time and should be supported radiographically, if possible. However, it is believed that early mineralization can be detected histologically 12 weeks before it is apparent 
on radiographs (4). This is because there must be sufficient deposition of hard tissue (for absorption of $\mathrm{X}$-rays) to become evident on radiographs.

The timing and sequence of the various stages of growth in the developing dentition follow a very strict pattern, particularly before and after birth. Subsequently racial and familial factors dominate, in addition to environmental and nutritional factors that affect the patho-physiological changes that occur on them (5-7). Studies have shown that the contribution of common environmental effects or so-called maternal effects to the tooth size variation appears to be more pronounced in the deciduous dentition than the permanent - probably due to earlier development. Garn et al (8) showed that maternal diabetes, maternal hypothyroidism, and large size at birth are associated with larger maxillary and mandibular teeth. Conversely, deciduous and permanent tooth size is reduced in maternal hypertension, or low birth weight and small sized babies.

The incremental pattern of mineralisation of developing teeth is subject to periodic disturbances. Birth, diseases, drug intake, trauma and dietary changes can all cause changes in the incremental pattern. These changes can be detected and in some instances, be retrospectively linked to a specific time or event during the individual's life (4). Dental mineralization is a better measure than skeletal development because tooth formation is comparatively less modified by malnutrition and hormonal imbalance. Furthermore, teeth being the hardest calcified tissue tend to be intact even when other components of the skeleton disintegrate (9). The high survivability of teeth to severe physical conditions, such as heat, cold, fire and chemicals make assessment of the developing teeth the method of choice in forensic investigation. They are also well represented in fossilized remains and have provided a large amount of metric and morphologic data relating to hominid evolution (10).

Examination of the developing teeth in a foetus will reveal in addition to its age, other medico-legally important information viz. viability of the foetus; whether it was born alive and whether it had a separate existence. The presence of the neonatal lines in enamel and dentine positively indicates life after birth (11).

The enamel and dentine formed during the intrauterine period is often of good quality (usually homogenous) as there are relatively few nutritional disturbances before the child is born. According to Ten Cate (12) coronal dentine is laid down at a rate of 4 $\mu \mathrm{m}$ per day, thereby making it possible to determine the age of an infant both during the intrauterine period and some months after birth. This is done by measuring the amount of dentine laid down after the neonatal line or the "birth line" (a distinct line which demarcates the mineralization before and after birth). Similarly, there is evidence to suggest that the intervals between crossstriations in enamel rods or prisms represent the amount of enamel formed per day, approximately $4 \mu \mathrm{m}$ (13). The neonatal line evidences a change in the normal enamel apposition. This marker is not apparent in all cases, so a false negative result can be produced under light microscope (14). Ciapparelli (4) quoted that according to work done by Bamford in 1985, the detection of the neonatal line depends on the axis of the tooth section, section thickness and the light source used. Therefore, the absence of this line is not an indication of still birth. Furthermore, for such a neonatal line to be clearly visible with light microscope, a reasonable thickness of postnatal enamel has to be produced. In practice, this means that the method can be used only if the child survives for about three weeks after birth (15). However, Whittaker and Richards (16) have demonstrated that neonatal lines occurred in all 50 teeth examined and they measured these lines using scanning electron microscope techniques. Scanning electron microscopy allows for much higher resolution than the light microscope. The individual rod or prisms making up the structure of enamel can be easily seen, although they are no more than $5 \mu \mathrm{m}$ in diameter. At the time of birth there is sufficient disturbance to produce structural changes in these rods. These changes may be a disturbance in crystal growth, a change in direction of the rods, or simply an alteration in their dimension. According to Whittaker and MacDonald (15) it should be possible to distinguish postnatal enamel from prenatal enamel within a day or two after birth. It must be further remembered that all deciduous and the 1st permanent molar teeth develop during the foetal stage. The fragments are small and such pieces can easily be lost, should the foetus be unnecessarily disturbed. The calcified part of the 1st permanent molar is only about the size of pinhead at birth and possibly weighing about $1 \mathrm{mg}$ (17). This is the reason why radiography is advantageous in locating them because it is not mutilating. Furthermore in decomposed remains, developing mineralized tooth cusps will have lost their soft-tissue support and will be found lying loose in the dental crypts. Once detected radiographically, removal and closer examination of the developing teeth can be made easier.

\section{CASE REPORT}

A box containing a male human foetus was found floating in a river. No clothing was found and it was in a moderate state of putrefaction. The umbilical stump measured $2.5 \mathrm{~cm}$., was not ligated and its free end was macerated owing to putrefaction and hence it could not be established whether it was cut or torn. There were several surface and penetrating postmortem wounds; the latter were extending into the body cavities. The head appeared collapsed owing to over riding of skull bones and internal visceral organs had mostly perished, partly due to putrefactive dissolution and partly eaten up by maggots. The foetus measured around $51 \mathrm{~cm}$ (crown-heel length), weighed $1 \mathrm{~kg}$ and head hair measured $2 \mathrm{~cm}$. Thecrown-heel length was very approximate because of the collapsed skull bones and excessive stretching of the body and limbs at various joints. It was felt that the measurement was in excess of the actual length of the foetus. The weight on the other hand was less than the 


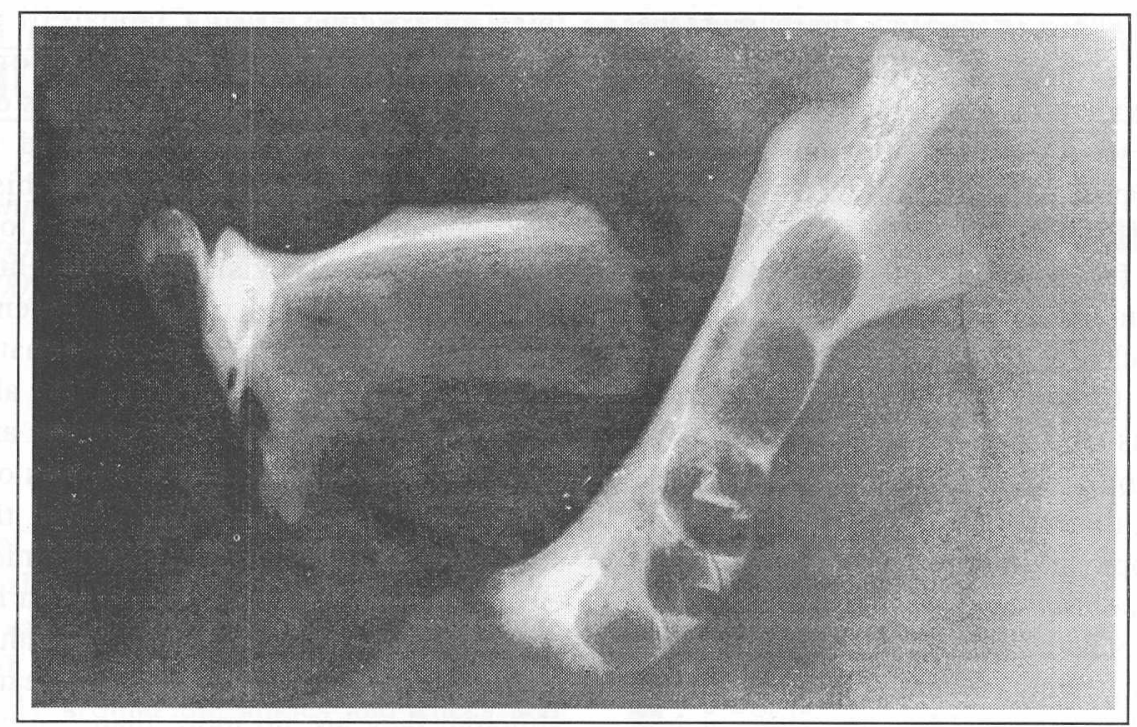

Figure 1: Radiograph shows the developing teeth in the right mandible.

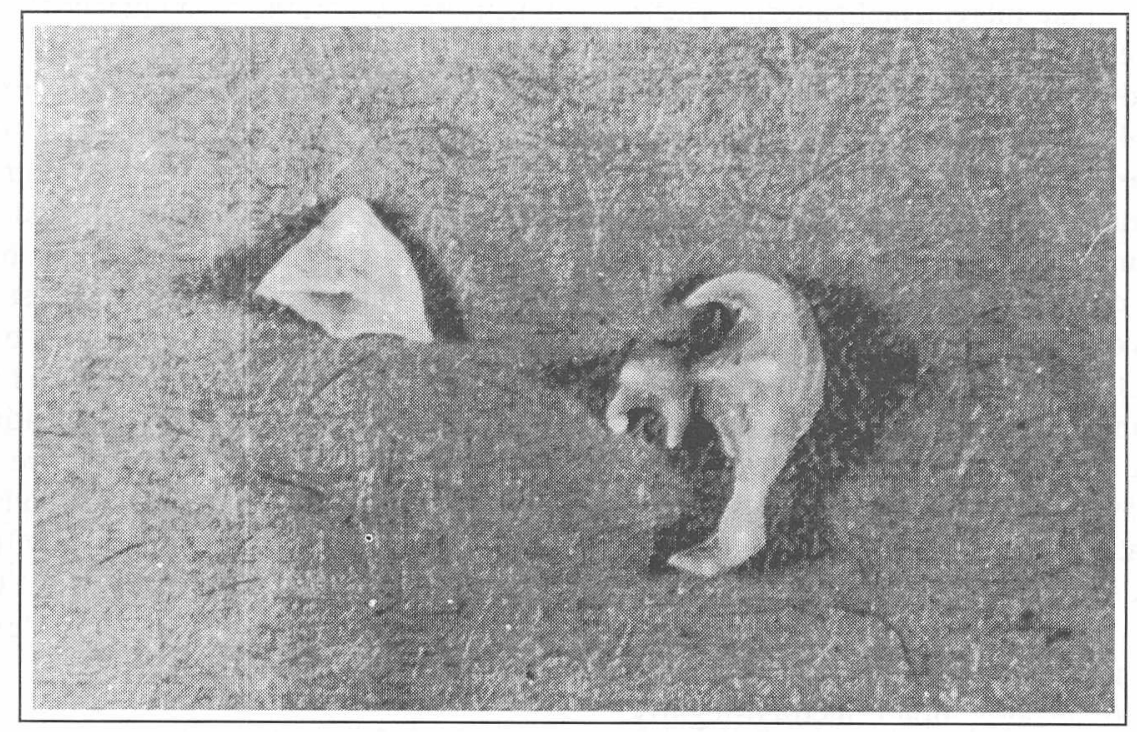

Figure 2: Shows the stage of development of the right first deciduous molar and deciduous canine.

actual weight owing to putrefaction and the loss of visceral organs being eaten up by maggots. Ossification centres were present in the manubrium and the sternum (first three parts), calcaneum, talus and cuboid in the ankle and lower femur and upper tibia in the knee. The approximate estimated age of maturity was around nine months intrauterine. It was not possible to draw any conclusion as to whether it was a live birth and whether there was a separate existence. The remains were then subjected to a dental examination.

In this case study a co-relationship was made to determine the reliability of estimation of prenatal dental age from teeth with other medical parameters. The right and left side of the mandible was retrieved. Radiographs of the mandible bones were taken using dental X-ray films. It was noticed that the occlusal bony covering of all the dental crypts were non-existent. But it was observed that the developing 1st deciduous molar and canine teeth were present in their respective crypts of the right side of the mandible only. These developing teeth were then removed and studied closely under bright light.

\section{1) DECIDUOUS RIGHT CANINE (Tooth} Only the cusp tip had formed.

\section{2) FIRST RIGHT DECIDUOUS MOLAR (Tooth $\ddot{*} 84$ )}

There was direct union of the mesiobuccal and mesiolingual cusps with the coalescence of the distal and distobuccal cusps. There was also the calcified extension from the mesiobuccal cusp which had not fused with the mesiolingual cusp. 
The results in accordance to the research by Kraus \& Jordan (3) on prenatal growth of deciduous teeth indicated that the stage of development of the 1st deciduous molar was consistent with a foetal age of approximately 30-32 weeks intrauterine. This was comparably close to the age estimated from ossification centres of various bones of the foetus.

\section{DISCUSSION}

Putrefaction and disintegration of foetal remains pose problems in medico-legal investigation of such deaths. Maturity of the foetus and in turn the viability, the possibility of live birth and a separate existence are important questions that have to be addressed (18). According to the Malaysian Penal Code Section 309A, infanticide means where a mother by any wilful act or omission causes the death of her newly-born child, but at that time of commission or omission the balance of her mind was disturbed by pregnancy, labour or lactation (19). The Sri Lankan Penal Code on the other hand does not have a separate infanticide act but infanticide is covered under section 294, exception 5 that deals with culpable homicide not amounting to murder (20). Under this section the age of the infant extends up to 12 months and the offender can only be the mother. Statistically, such an act invariably occurs at the time of birth or shortly after. To succeed in a case of alleged infanticide the pathologist should be able to establish not only a separate existence but that death was due to an intentional violence or negligence. Otherwise the charge will fail and if the remains were found at an inappropriate site then the woman could be charged only for concealment of birth. Furthermore, generally the law presumes that an infant is born dead unless proved otherwise (21).

Conversely, the law pertaining to child murder or filicide is different. According to section 299 of the Malaysian Penal Code, causing the death of a living child, if any part of that child has been brought forth, though the child may not have been breathed or been completely born amounts to culpable homicide (22). This section presumes the child to have been born alive unless proved otherwise.

Legal authorities agree that if the foetal age is around 28 weeks, it could be assumed that the infant to be still born or that it died shortly after birth due to prematurity. In this particular case the foetus however had reached sufficient maturity (30-32 weeks) and we can suspect that the baby could have been born alive and had separate existence.

If the foetus was fresh and intact, it may be possible to determine whether the child actually had an independent existence by observing changes in the lungs, any extraneous material in the air passage, determining the evidence of feeding, healing of the umblical stump and so on. In this case the question of live birth and a separate existence remains unanswered owing to putrefaction. Dental examination was not carried out to establish the presence of a neonatal line in the hard tissue. However, the absence of neonatal line does not necessarily exclude live birth because a couple of days of survival is necessary before the neonatal line could be detected by electron microscopy in the dental tissues. Furthermore as indicated earlier, it is important to remember that most cases of infanticide occur at the time of or shortly after birth, and hence if at all there is a only a very brief period of separate existence of the child from the mother. In this case the mother was not identified, and even if she is identified, a charge of infanticide or filicide will not succeed owing to the inability to establish live birth and a separate existence. Besides due to putrefaction of the foetus, it is not possible to determine any form of subtle physical violence. The mother can however be charged for concealment of a birth.

\section{CONCLUSION}

Dental age is estimated by comparing the dental developmental status of a person of unknown age with published dental development or eruption surveys (4). By so doing, the likely chronological age for the individual can be successfully deduced. The chronological or real age is measured by the calendar. The biologic (physiologic or developmental) age is however determined by referring to a chart illustrating stages of dental development known to occur at a particular time amongst the general population (18). Various standardized dental development charts or surveys have been produced after exhaustive studies have been made carefully. Some have stressed that in selected cases, age determination up to few months are possible, especially the intrauterine development and the early years of one's life. These charts can be employed as valid methods to determine not only the age of human remains in forensic cases but also in archaeological excavations. Caution must be expressed that estimating age from biological material cannot be equated absolutely with the chronological age because of variation due to race, environment and nutrition amongst different individuals. Besides, in this particular case we found the age estimated from developing dental tissues (30-32 weeks) was slightly less than when employing ossification centres ( 9 months) as the method of estimation. Probably this is an incidental isolated finding and further research may be necessary to correlate both these methods of age estimation.

\section{REFERENCES}

1. Miles AEW. The assessment of age from dentition. Pro Roy Soc Med 1958; 52: 1057- 60.

2. Altini M. Age determination from the teeth - a review. J Dent Assoc S Africa 1983; 38: 275-8. 
3. Kraus BS, Jordan RE. The mandibular first primary molar. In: The dentition before birth. Philadelphia: Lea and Febiger 1965: 39-53.

4. Ciapparelli L. The chronology of dental development and age assessment. In: Clark DH, ed. Practical forensic odontonlogy. 1st ed. ButterworthHeinmann Ltd 1992: 20-40.

5. Bailit HL, Sung B. Maternal effects on the developing dentition. Arch Oral Biol 1968; 13: 155 61.

6. Noble HW. The estimation of age from the dentition. In: Harvey W, ed. Dental identification and forensic odontology. Henry Kimptom Publisher 1976: 28-34.

7. Miles AEW. Teeth as an indicator of age in man. In: Butler PM \& Joysey KA, ed. Evolution of teeth. Academic Press 1978: 455-464.

8. Garn SM, Osborne RH, Alvesalo L, Horowitz SL. Maternal and gestational influences on deciduous and permanent tooth size. J Dent Res 1980; 59: 1423.

9. Burn KR, Maples WR. Estimation of age from the individual adult teeth. J For Sci 1976; 21: 343-56.

10. Townsend GC. Anthropological aspects of dental morphology with special reference to tropical population. In: Prabhu SR, Wilson DF, Daftary DK \& Johnson NW, eds. Oral diseases in the tropics. Oxford: Oxford University Press 1992: 45-58.

11. Whittaker DK. Forensic dentistry in the identification of victims and assailants. J Clin For Med 1995; 2: 145-51.

12. Ten cate AR. Dentinogenesis. In: Ten Cate AR, ed. Oral Histology, Development, Structure and Function, $4^{\text {th }}$ Edition. Mosby year Book, Inc 1994: 147-68.
13. Eisenmann DR . Enamel structure. In: Ten Cate AR (ed).Oral Histology, Development, Structure and Funtion, $4^{\text {th }}$ Edition. Mosby year Book, Inc 1994: 239-56.

14. Bowers CM. Age determination - Determining age from teeth: The estimation of age from dental development. In: Bowers CM \& Bell GL, ed. Manual of forensic odontology. 3rd edition. American Society of Forensic Odontology 1991: 75 -85 .

15. Whittaker DK, MacDonald DG. Age determination from the teeth. In: Colour atlas of forensic dentistry. Wolfe Publishing Ltd 1989: 58-66.

16. Whittaker DK, Richards D. Scanning electron microscopy of the neonatal line in human enamel. Arch Oral Biol 1978; 2: 145-151.

17. Clement JG, Kosa F. The fetal skeleton. In: Clark $\mathrm{DH}$, ed. Practical forensic odontonlogy. 1st Edition. Butterworth-Heinmann Ltd 1992: 43-52.

18. Moorrees CFA, Fanning EA \& Hunt Jr. EE. Age variation of formation stages for ten permanent teeth. J Dent Res 1963; 42: 1490-1502.

19. Penal Code of Malaysia (F.M.S. Cap 45), section 309A, Infanticide.

20. Penal Code of Sri Lanka. Section 294, exception 5 , culpable homicide not amounting to murder.

21. Knight B. Infanticide and stillbirth. In: Forensic Pathology. $1^{\text {st }}$ Edition. Edward Arnold, 1991: 40213.

22. Penal Code of Malaysia (F.M.S.Cap 45). Section 299, culpable homicide, exception 3. 